\title{
THE ULTRASTRUCTURE OF HUMAN DECIDUAL AND PREDECIDUAL CELLS
}

\author{
A. M. LAWN, E. W. WILSON AND G. A. FINN \\ Lister Institute of Preventive Medicine, London, \\ Department of Obstetrics and Gynaecology, The University of Sheffield, \\ Jessop Hospital for Women, Sheffeld, and \\ Royal Veterinary College, University of London
}

(Received 25th August 1970)

\begin{abstract}
Summary. Human decidual cells possess 'gap' junctions but they connect processes from the same cell and do not join neighbouring cells. They are, therefore, unlikely to contribute to the efficiency of the decidua as a mechanical barrier, in contrast to similar junctions in mouse decidua which do join neighbouring cells. Mature human decidual cells are surrounded by a layer of dense extracellular material indistinguishable from the basement membrane of epithelial cells. Predecidual cells in human endometrium in the late luteal phase of the menstrual cycle have 'gap' junctions which, as in pregnant mice, join neighbouring cells.
\end{abstract}

\section{INTRODUCTION}

Decidual cells in the endometrium of mice during early pregnancy are joined to one another by specialized junctions (Finn \& Lawn, 1967). If these junctions are associated with some important general function of decidual cells then they should be found between the endometrial decidual cells of other species. They are present between the decidual cells of rodents such as the lemming and the hyrax (unpublished observations) but have not been described previously in human pregnancy. In this account, the specialized junctions of human decidual cells as seen in electron micrographs are described and compared with those between predecidual cells in the human endometrium during the late luteal phase of the menstrual cycle.

\section{METHODS}

Decidual tissue was obtained at hysterotomy or hysterectomy for termination of pregnancy, a distinction being preserved between tissue obtained from beneath the placental site and that obtained away from the placental site. Pregnancies were dated from the lst day of the last menstruation. Endometrium was obtained by uterine curettage: dating was from the 1st day of the last menstruation.

The tissue was cut into small pieces and fixed in $6.5 \%$ glutaraldehyde in 0.1 M-phosphate buffer at $\mathrm{pH} 6.8$ for 6 to $8 \mathrm{hr}$ in the cold. A few specimens were 
fixed in $3 \%$ glutaraldehyde in $0.01 \mathrm{M}$-cacodylate buffer at $\mathrm{pH} 7.4$. After primary fixation, the tissue was transferred to buffer alone for a variable period until further processing was started.

Post-fixation was in $1 \%$ osmium tetroxide in $0.1 \mathrm{M}$-veronal acetate buffer, followed by dehydration and embedding in Araldite. Sections were stained routinely with lead acetate.

\section{RESULTS}

\section{Decidual cells during pregnancy}

In an attempt to avoid possible confusion of identity between trophoblast and decidual cells, the examination was confined to parietal decidua and to those regions of the basal decidua remote from the trophoblastic shell. At the end of the first trimester, masses of well-differentiated large spherical decidual cells were observed in both these regions. Towards the myometrium, the spherical

\section{EXPLANATION OF PLATES}

\section{PLATE 1}

Fig. 1. A decidual cell with two neighbouring leucocytes from the parietal decidua of a woman 3 months pregnant.

FIG. 2. Club-shaped processes protruding from the surface of a decidual cell. Several processes contain granules, and a gap junction joins two processes apparently separate from the cell (arrow). A basement membrane-like layer coats the cell surface except that of the processes $(\mathrm{bm})$.

\section{PLATE 2}

Fig. 3. Part of the external surface of a capillary (cap) and a neighbouring decidual cell (dec). The basement membrane-like layer of the decidual cell is similar to, although thinner than, the basement membrane of the capillary.

Fig. 4. Gap junctions between processes at the surface of a decidual cell after block staining with uranyl acetate. The outer leaflets of the plasma membranes continue into the junctions, where they remain separated.

FIc. 5. In this section (not block stained with uranyl acetate), the outer leafiets of the plasma membranes at junctions between decidual cell processes appear to be replaced by a row of dense particles. Note the membrane-bound granule in the upper cell process.

Fig. 6. This portion of a gap junction between two decidual cell processes clearly shows that the outer leaflets of the plasma membranes are not fused (block stained with uranyl acetate).

\section{PLATE 3}

Figs. 7 and 8 . These two micrographs are from a series of serial sections. The two processes which are joined by a specialized junction are both from the same cell, although this was not apparent in any of the individual sections. Note the endoplasmic reticulum related to the cell surface in Fig. 8.

FIG. 9. This grazing section of the surface of a decidual cell demonstrates the large number of cell processes which may be present. Most of these processes contain membranebound granules.

PLATE 4

Fig. 10. Endometrial stromal cells 10 to 11 days after menstruation. A leucocyte (leu) lies near a small capillary (cap).

Fig. 11. Fibroblasts from the endometrial stroma in the luteal phase of the menstrual cycle.

PLATE 5

Fig. 12. Predecidual cells near a small arteriole in the endometrial stroma 29 days after menstruation.

Fig. 13. A specialized junction between two predecidual cells in the endometrial stroma in the luteal phase of the menstrual cycle. 

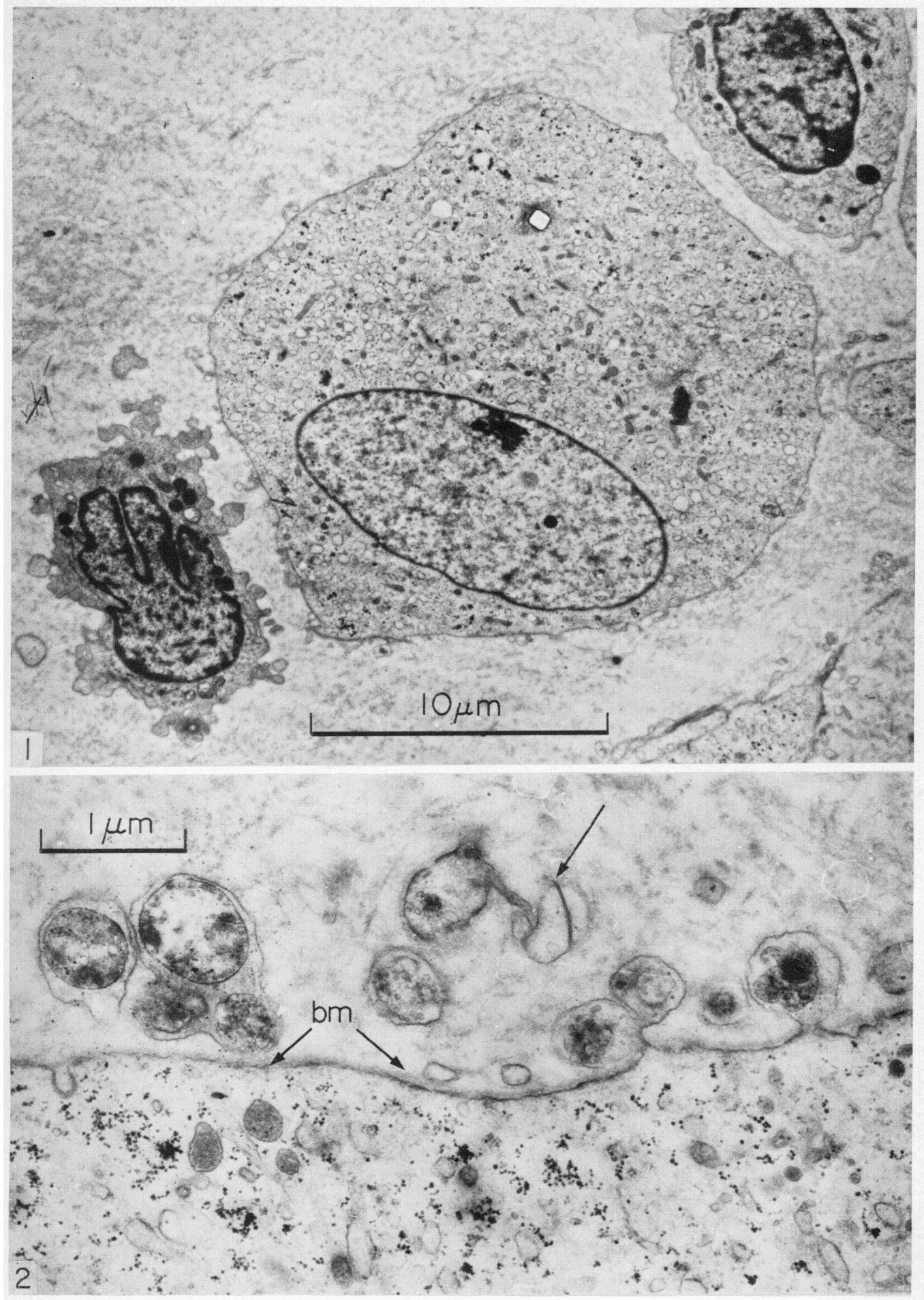

(Facing p. 86) 
PLATE 2
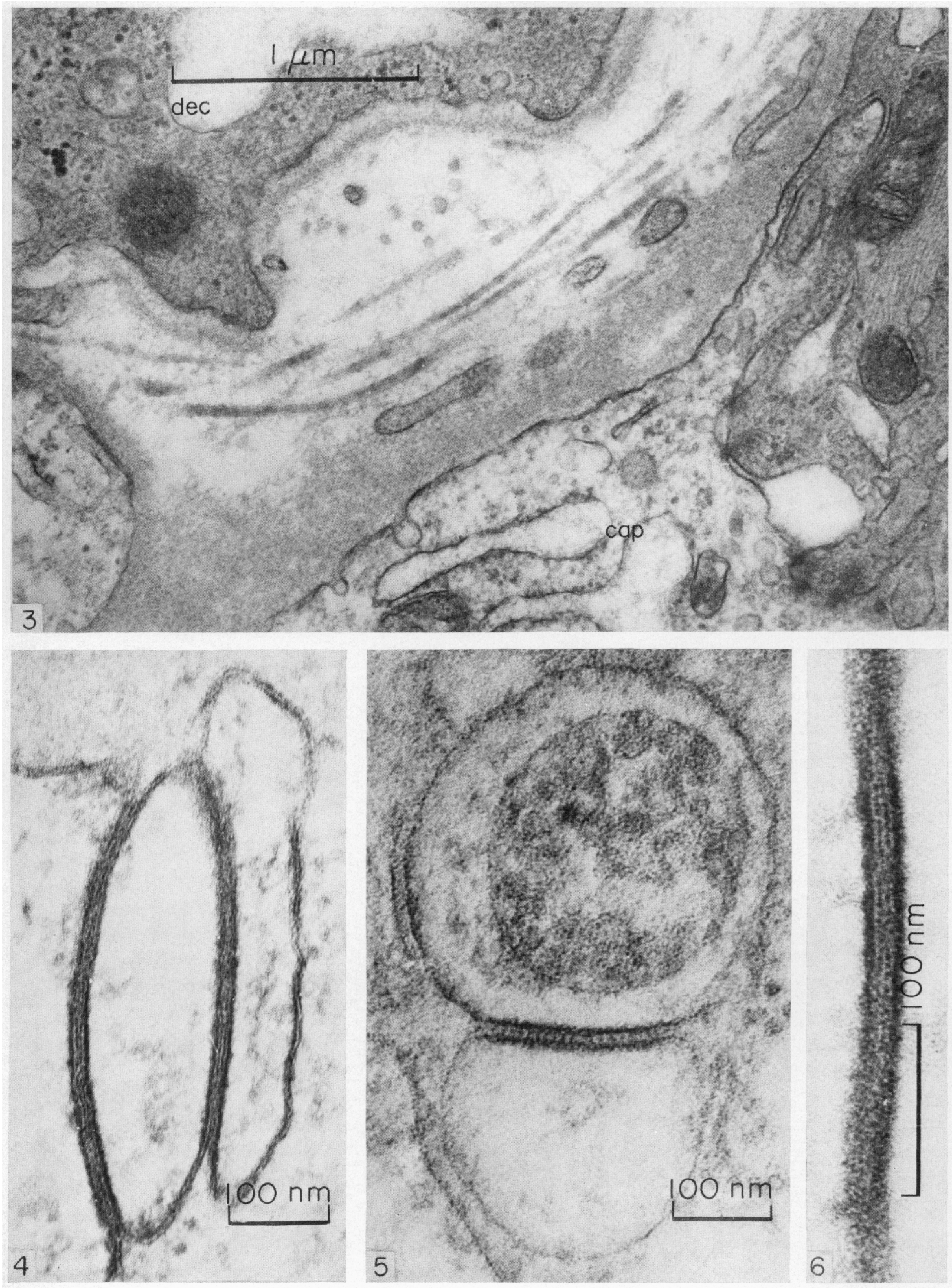
PLATE 3
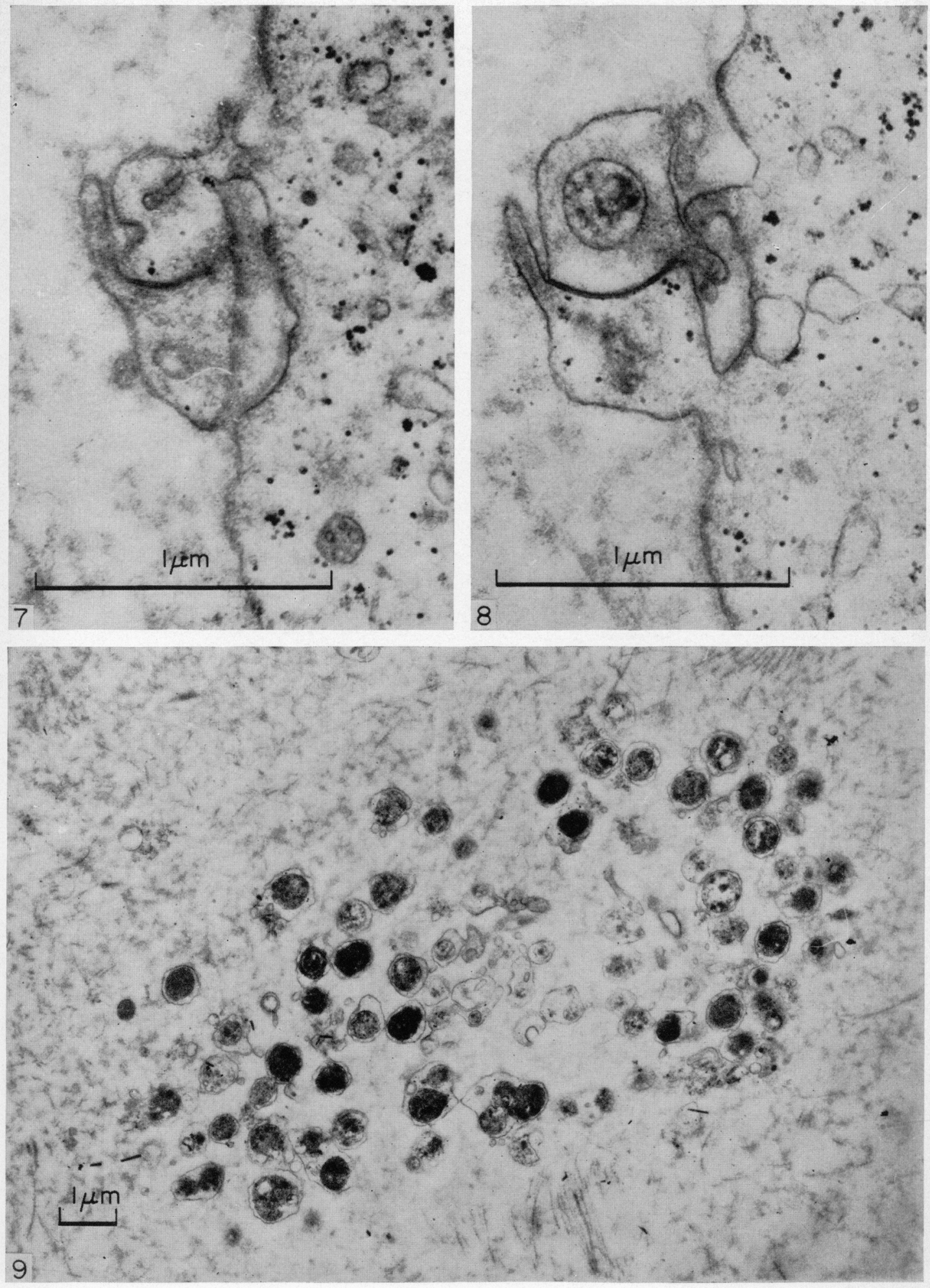
PLATE 4
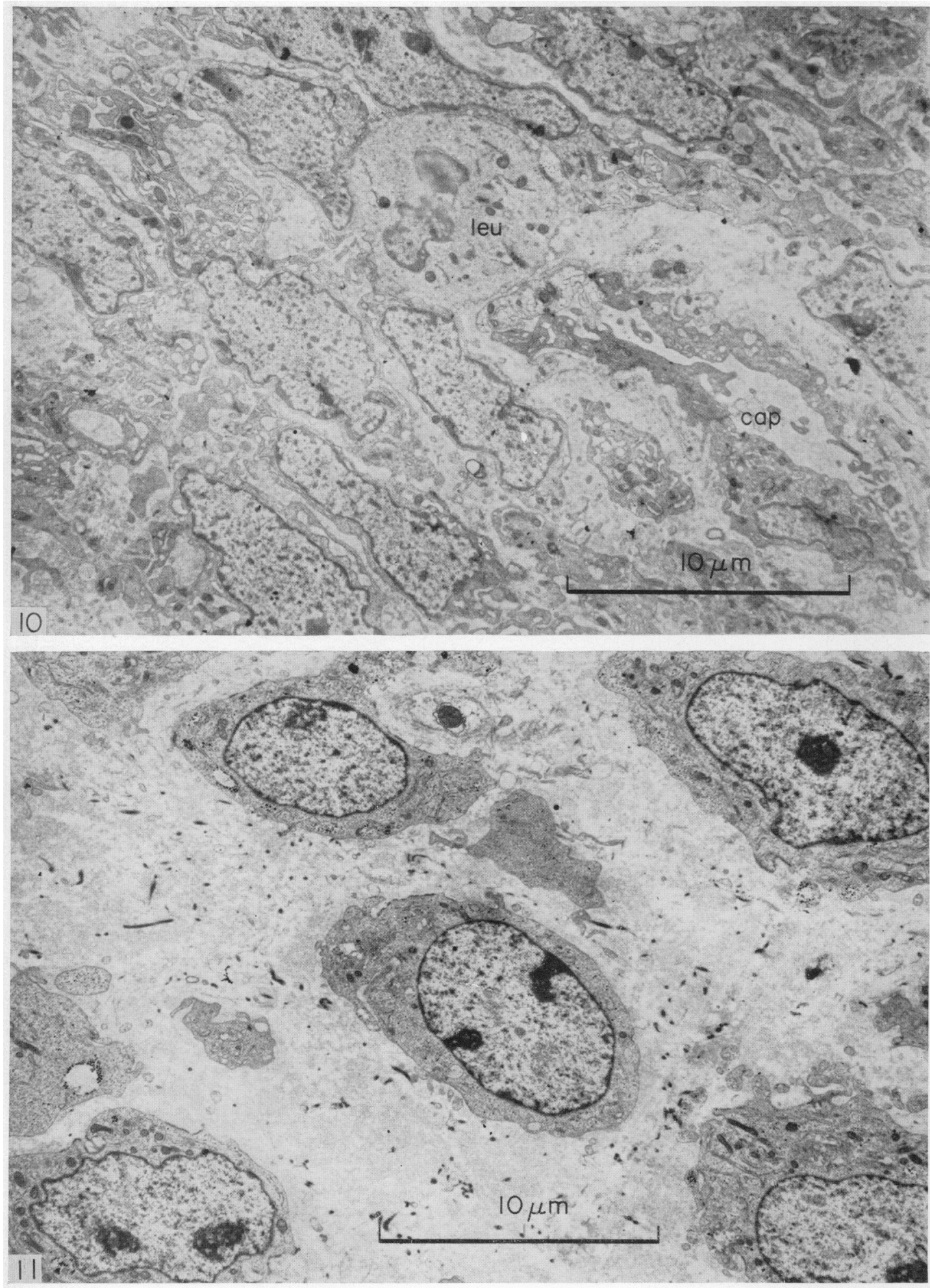
PLATE 5
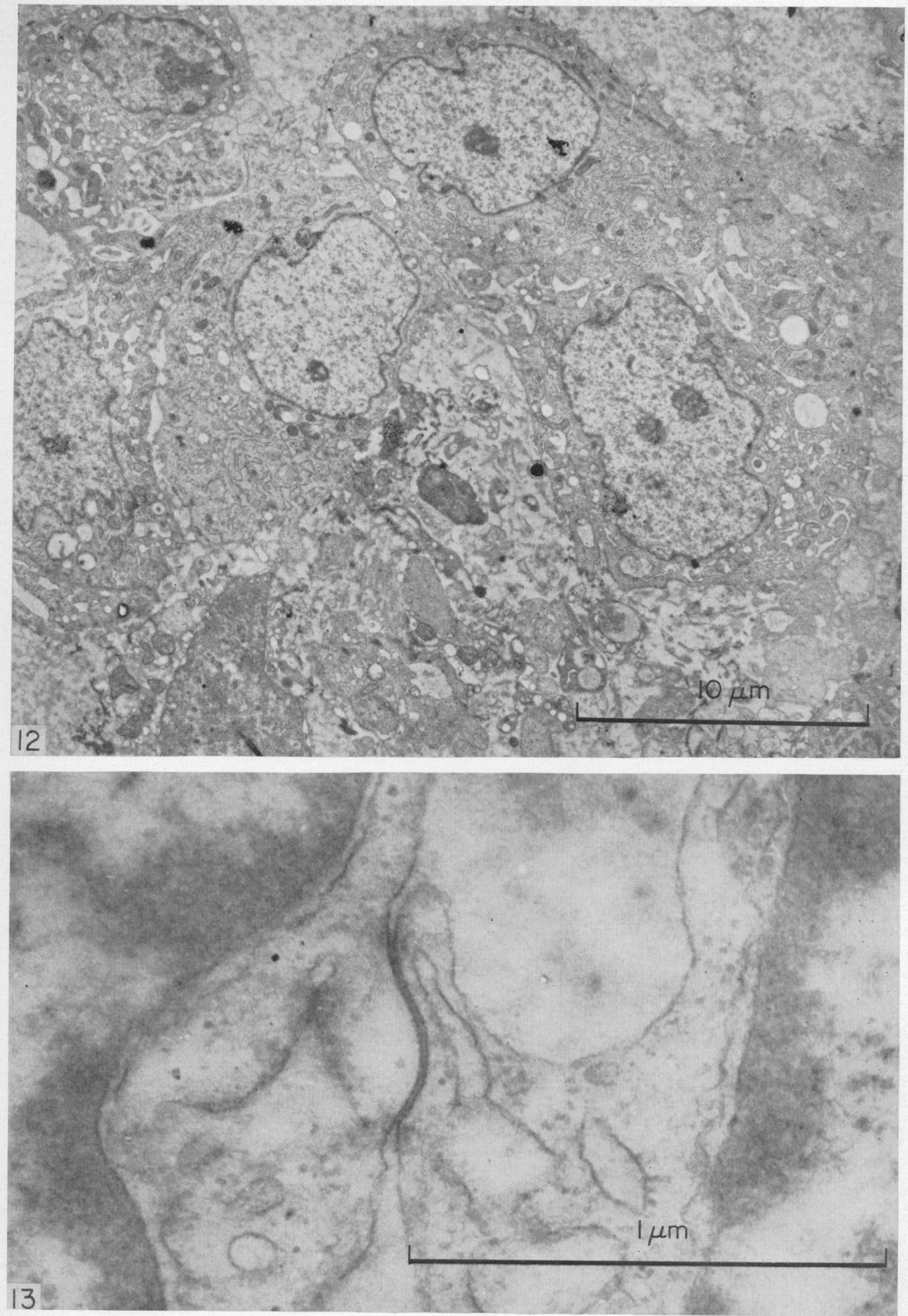
cells were replaced by irregular decidual cells and then by spindle-shaped cells resembling undifferentiated stromal cells.

Only the surface features of the decidual cells are described below in detail. Other features are described by Wynn (1967) and Enders (1968). At the end of the first trimester, except for the largest and most differentiated cells, decidual cells were well separated from each other (Pl. 1, Fig. 1) by an extracellular matrix, much of which was in the form of fibrils exhibiting banding of the collagen type. Processes joining one cell to another were rare.

The well differentiated spherical decidual cells had a dense rim (Pl. 1, Fig. 2) extending over most of the circumference. This was produced by a condensation of the cytoplasm internal to the plasma membrane and a basement membranelike condensation of the intercellular matrix external to the membrane (Pl. 1, Fig. 2; Pl. 2, Fig. 3). As this external material is morphologically indistinguishable from the basement membrane enclosing neighbouring small blood vessels (Pl. 2, Fig. 3), it will hereinafter be called a basement membrane. Short, often club-shaped, processes protruded through gaps in the basement membrane (Pl. 1, Fig. 1; Pl. 3, Figs. 7, 8 and 9). Some of these processes were branched and some appeared as though separate from the body of the cell, presumably because of the plane of section. The processes frequently contained membranebound spherical inclusions, which in turn contained dense amorphous, vesicular or granular material. A number of neighbouring processes were joined to one another at specialized regions of the plasma membrane. Here, the outer leaflets in specimens block-stained with uranyl acetate were in close proximity and parallel (Pl. 2, Figs. 4 and 6) or replaced by a series of granules (Pl. 2, Fig. 5). The inner leaflets were thickened and more dense than in neighbouring unspecialized membrane. These specialized junctions were identical with the gap junctions described between cells in the central nervous system (Brightman \& Reese, 1969), hepatocytes (Benedetti \& Emmelot, 1965; Revel \& Karnovsky, 1967) and in smooth and cardiac muscle (Dewey \& Barr, 1964; Revel \& Karnovsky, 1967; Cobb \& Bennett, 1969). Because of the separation between decidual cells in this region and the absence of processes in the intercellular matrix, it seemed unlikely that these specialized junctions formed a connection between the processes of one cell and those of another. Serial sections in a number of cases (Pl. 3, Figs. 7 and 8) confirmed that the functions joined processes arising from the same cell.

Where decidual cells were largest and most differentiated, the amount of matrix was less. The surface processes were flattened and contained few of the membrane-bound inclusions described above, but specialized gap junctions were present.

The surface of the less differentiated, irregularly shaped decidual cells was extended into many large branched processes, parts of which were joined by specialized gap junctions. Membrane-bound inclusions were infrequent in these processes. The surface of these cells was only partly covered by basement membrane, but when present it was associated with the characteristic thickening of the plasma membrane. Processes often joined to form bridges enclosing (in that particular section) a mass of matrix within the perimeter of the cell. This connection was often effected by means of gap junctions. 


\section{Predecidual cells in the endometrium during the menstrual cycle}

Although, in the pregnant uterus at 3 months' gestation, specialized junctions were found only between processes from the same cell, it was thought that intercellular junctions might be present in developing decidual tissue earlier in pregnancy, when the time after induction of decidual cell formation was more comparable with that at which such junctions are abundant between decidual cells in mice. As specimens from early pregnancy were not available, tissue from the cycling endometrium was examined. In the late luteal part of the cycle, predecidual cells with some of the characteristics of decidual cells have been described (Noyes, Hertig \& Rock, 1950). The general ultrastructural features of stromal cells in the cycling endometrium have been described by others (Wynn, 1965; Wynn \& Harris, 1967; Wynn \& Woolley, 1967; Wienke, Cavazos, Hall \& Lucas, 1968). Owing to the loss of superficial tissue and its regeneration during the menstrual cycle, the rather well-ordered pattern characteristic of the rodent endometrial stroma was absent. Stromal cells differed in structure not only at different times in the cycle but at different sites in the endometrium and even neighbouring cells differed considerably. Furthermore, there were many wandering macrophages and leucocytes which could be confused with stromal cells. In spite of this variability, a general trend of development from less differentiated stromal cells to predecidual cells could be established in the material available.

At 11 and 17 days after the commencement of menstruation, stromal cells possessed relatively little cytoplasm and the nucleus was elongated and indented (Pl. 4, Fig. 10). Only small patches of the plasma membrane were thickened, these thickenings being found even in the least differentiated stromal cells near the myometrium, but the endoplasmic reticulum was well developed. Despite a thorough search of many fields of cells, only a few specialized junctions were found at this stage of the cycle although, in many regions, there was little matrix and extensive contact of the non-specialized kind between cells.

Towards the end of the luteal phase of the cycle, stromal cells could be found, particularly near small arterioles, which possessed more of the characteristics of mature decidual cells (Pl. 5, Fig. 12). In these regions, gap junctions were easily found between neighbouring cells (Pl. 5, Fig. 13) although they were not as frequent as in mouse decidual tissue. The development of the endoplasmic reticulum was more advanced than earlier in the cycle and a characteristic association between this and the plasma membrane suggested that these cells were actively secreting (this association was also found in the decidual cells of pregnancy). Matrix was more abundant than in the 11- and 17-day stroma. These predecidual cells near small arterioles correspond to cells which possess alkaline phosphatase activity at this stage of the cycle (Wilson, 1969). Strong alkaline phosphatase activity is typical of mouse decidual cells in early pregnancy (Finn \& Hinchliffe, 1964, 1965).

Specialized junctions could be found only rarely in the widely separated somewhat rounded cells occurring in areas near large blood vessels (Pl. 4, Fig. 11). Such cells are alkaline phosphatase negative (Wilson, 1969) and are probably differentiated fibroblasts. 


\section{DISCUSSION}

In spite of the discrepancy in the duration of the decidual reaction, human decidual cells at 3 months' gestation and mouse decidual cells at 7 to 9 days' gestation have many features in common. Both are large cells containing much glycogen and intracellular fibrils, and have a moderately developed endoplasmic reticulum whose relationship to the plasma membrane suggests secretory activity. However, human decidual cells are separated by abundant matrix and lack the processes joining one cell to another by specialized gap junctions which are typical of mouse decidual cells. Instead, the gap junctions join individual processes from the same cell.

These junctions in human decidual cells must be part of the decidual transformation because they are rare in the endometrium, except in the late luteal part of the menstrual cycle when the hormonal effect of the corpus luteum begins. At this time, predecidual cells are often in contact with each other as matrix is less abundant than during pregnancy. Intercellular gap junctions are found and the cells are comparable in structure with mouse decidual cells on Day 5 of pregnancy. Later, these intercellular junctions disappeared. In mice, there is no luteal phase in the oestrous cycle and mating is required before decidual cell formation, with the formation of intercellular junctions, can occur.

The fibroblast-like cells of the human endometrium in the luteal phase of the cycle do not respond to the luteal hormones by the formation of gap junctions and the presence of alkaline phosphatase activity. This may be because they have reached a stage of differentiation at the time of ovulation which makes them insensitive to the stimulus for decidual cell formation which only affects the undifferentiated stromal cells.

Gap junctions between cells in the nervous system, liver, embryonic tissue and muscle are believed to be associated with high electrical conductivity and ionic permeability between one cell and another (Loewenstein, 1966). It has been suggested that the development of this type of connection between mouse decidual cells is associated with a change from independent stromal cells into a coordinated assembly of interconnected cells forming a decidual 'organ' (Finn \& Lawn, 1967). As differentiated human decidual cells are not joined to each other in this way, intercellular junctions cannot be essential for decidual function in all species. It is difficult to imagine a useful function for junctions joining parts of the same decidual cells. They do not consolidate the decidual tissue and therefore are unlikely to contribute to the limitation of trophoblastic invasion or to mechanical protection of the conceptus, which are possible functions in rodents. In women, the abundant extracellular matrix may be the more important mechanical structure. It could be supposed that the predisposition to form gap junctions between adjacent cell membranes is a symptom of a more fundamental epithelioid change in membrane structure which is characteristic of the decidual transformation.

Published accounts of decidual cells of rats and mice (Jollie \& Bencosme, 1965; Finn \& Lawn, 1967; Enders \& Schlafke, 1967) do not describe a basement membrane, although one is sometimes found in the mouse after Day 8 
of pregnancy confined to the decidual cell surfaces which face blood vessels (Lawn, unpublished). The presence of a basement membrane and thickenings of the plasma membrane in human decidual cells is not solely because of the longer duration of decidual cell formation, because thickenings are present even in undifferentiated stromal cells.

The membrane-limited inclusions within processes from the surface of human decidual cells have not previously been described. These structures were virtually absent from the cell body and there was no clear indication of their origin. They could be a secretory product on the one hand or the residue of intracellular digestion on the other.

\section{REFERENCES}

Benedetti, E. L. \& Emmelot, P. (1965) Electron microscopic observations on negatively stained plasma membranes isolated from rat liver. F. Cell Biol. 26, 299.

BrightMAN, M. W. \& ReEse, T. S. (1969) Junctions between intimately apposed cell membranes in the vertebrate brain. 7. Cell Biol. 40, 649 .

CoBb, J. S. \& Bennetr, T. (1969) A study of the nexus in visceral smooth muscle. F. Cell Biol. 44, 287.

DewEy, M. M. \& BARR, L. (1964) A study of the structure and distribution of the nexus. F. Cell Biol. 23, 553.

Enders, A. C. (1968) Fine structure of anchoring villi of the human placenta. Am. F. Anat. 122, 419.

ENDERs, A. C. \& Schlafke, S. (1967) A morphological analysis of the early implantation stages in the rat. Am. 7. Anat. 120, 185.

Finn, C. A. \& Hinchlifre, J. R. (1964) Reaction of the mouse uterus during implantation and deciduoma formation as demonstrated by changes in the distribution of alkaline phosphatase. J. Reprod. Fert. 8, 331.

Fins, C. A. \& Hinchlifre, J. R. (1965) Histological and histochemical analysis of the formation of implantation chambers in the mouse uterus. 7. Reprod. Fert. 9, 301.

FinN, C. A. \& LAwn, A. M. (1967) Specialized junctions between decidual cells in the uterus of the pregnant mouse. 7. Ultrastruct. Res. 20,321.

Jollre, W. P. \& Bencosme, S. A. (1965) Electron microscopic observations on primary decidua formation in the rat. Am. J. Anat. 116, 217.

Lokwenstein, W. R. (1966) Permeability of membranes: recent progress. Ann. N.Y. Acad. Sci. 137, 441.

Noyes, R. W., Hertig, A. T. \& Rock, J. (1950) Dating the endometrial biopsy. Fert. Steril. $1,3$.

Revel, J. P. \& Karnovsky, M. J. (1967) Hexagonal array of subunits in intercellular junctions of the mouse heart and liver. F. Cell Biol. 33, c7.

Wienke, E. C., Gavazos, F., Hall, D. G. \& Lugas, F. C. (1968) Ultrastructure of the human endometrial stromal cell during the menstrual cycle. Am. F. Obstet. Gynec. 102, 65.

Wrison, E. W. (1969) Alkaline phosphatase in pre-decidual cells of the human endometrium. $\mathcal{F}$. Reprod. Fert. 19, 567.

WynN, R. M. (1965) Ultrastructure of the developing decidua. Fert. Steril. 16, 16.

Wyns, R. M. (1967) Fetomaternal cellular relations in the human basal plate: an ultrastructural study of the placenta. Am. 7. Obstet. Gynec. 97, 832.

WYNN, R. M. \& HARRIS, J. A. (1967) Ultrastructural changes in the human endometrium. I. The normal preovulatory phase. Fert. Steril. 18, 632.

WYNN, R. M. \& Woolley, R. S. (1967) Ultrastructural cyclic changes in the human endometrium. II. Normal postovulatory stage. Fert. Steril. 18, 721. 